\title{
Frequency of isolation and drug susceptibility of bacterial strains isolated from child oncohematological patients 2011-2014: A single center study
}

\author{
Beata Kowalska-Krochmal ${ }^{1, A-F}$, Radosław Chaber ${ }^{2,3, A, C-F}$, Katarzyna Jermakow w,B,C, \\ Magdalena Hurkacz ${ }^{5, C}$, Elżbieta Piątkowska ${ }^{1, B}$, Grażyna Gościniak ${ }^{4, B, C}$, Grażyna Wróbel ${ }^{2, B, C, E, F}$ \\ ${ }^{1}$ Department of Pharmaceutical Microbiology and Parasitology, Wroclaw Medical University, Poland \\ ${ }^{2}$ Chair and Clinic of Pediatric Hematology, Oncology and Bone Marrow Transplantation, Wroclaw Medical University, Poland \\ ${ }^{3}$ Department of Pediatric Oncology and Hematology, Faculty of Medicine, University of Rzeszów, Poland \\ ${ }^{4}$ Chair and Department of Microbiology, Wroclaw Medical University, Poland \\ ${ }^{5}$ Chair and Department of Clinical Pharmacology, Wroclaw Medical University, Poland
}

A - research concept and design; $\mathrm{B}$ - collection and/or assembly of data; $\mathrm{C}$ - data analysis and interpretation; $D$ - writing the article; $E$ - critical revision of the article; $F$ - final approval of the article

Address for correspondence

Beata Kowalska-Krochmal

E-mail: beata.kowalska-krochmal@umed.wroc.pl

\section{Funding sources}

None declared

Conflict of interest

None declared

Received on November 16, 2016

Reviewed on January 28,2017

Accepted on February 15, 2017

DOI

10.17219/acem/69003

Copyright

Copyright by Author(s)

This is an article distributed under the terms of the

Creative Commons Attribution Non-Commercial License

(http://creativecommons.org/licenses/by-nc-nd/4.0/)

\begin{abstract}
Background. Infections in pediatric patients with oncohematological diseases pose a huge therapeutic and diagnostic problem.

Objectives. The aim of the study was to investigate the etiology of bacteremia and the antibiotic susceptibility of pathogenic and colonizing bacterial strains in pediatric oncohematological patients.

Material and methods. In the period 2011-2014, 17,209 positive test results, including 1,129 positive blood cultures, were subjected to a detailed analysis. The assessment of drug susceptibility was conducted in accordance with the CLSI (American), EUCAST (European), and KORLD (Polish) recommendations.
\end{abstract}

Results. A high percentage (86-91\%) of negative blood culture results was demonstrated. A predominance of Gram-positive bacteria was seen in all years (60-70\%) in contrast to Gram-negative strains (30-40\%). Coagulase-negative staphylococci (CNS) were the strains most frequently isolated from blood (41-47\%) among all bacterial strains. Susceptibility to linezolid and vancomycin was $96-100 \%$, and to teicoplanin 82-96\%. Methicyllin-resistant coagulase-negative Staphylococcus (MRCNS) were isolated in 77-86\%. All Staphylococcus aureus (S. aureus) strains were susceptible to glycopeptides and linezolid, while Enterococcus spp. was susceptible to linezolid. Apart from the year 2014, no methicillin-resistant S. aureus (MRSA) were isolated. Enterobacteriaceae (EN) were the most susceptible to imipenem and meropenem (91-100\%) as well as to amikacin (77-93\%). From 2013 to 2014, non-fermentative rods (NF) isolated from blood were less susceptible to imipenem and meropenem (71\% and 67-71\%, respectively) than to other antibiotics. It has been shown that strains isolated from blood have a statistically significantly different susceptibility to antibiotics (CNS and EN are less and NF is more susceptible) than those existing as colonizing flora.

Conclusions. Our results show that choosing appropriate antibiotics for treating infection in children with oncohematological diseases based on antibiograms for colonizing flora may be difficult because they may not take into account the more resistant strains. According to the antibiotic susceptibility of the strains isolated from blood in our center, the most viable active empirical and carbapenem-saving therapy could be conducted with piperacillin/tazobactam or cefepime.

Key words: antibiotic susceptibility, blood infections, oncohematological children 


\section{Introduction}

Infections in neutropenic patients in the course of cancer treatment and treatment of some hematological diseases constitute a significant factor which worsens the patients' condition and in some cases poses a direct threat to their life. The choice of antibiotic for treatment is difficult because it is nearly always empirical, owing to the time needed to wait for the results of microbiological tests. The spread of multi-drug-resistant pathogens additionally aggravates the already difficult decision-making process regarding antibiotic treatment. ${ }^{1}$ The assessment of the suitability of antibiotic therapy is also complicated by the fact that there are often problems with the identification of etiological factors despite the use of microbiological diagnostics. ${ }^{2-6}$ According to numerous reports, the negative test results of samples taken from seriously ill patients with clinically diagnosed infections unfortunately occur frequently, and account for as much as $80 \%$ of all samples in the case of blood cultures. ${ }^{2-4}$ Thus, for neutropenic patients with negative microbiological results of diagnostically relevant materials such as blood, it is important to identify the colonizing flora. Knowledge of the particular flora's drug resistance profile may be significant in enhancing the effectiveness of the therapy. ${ }^{1}$ In the case of neutropenic patients, there is a high risk of translocating endogenous flora from physiological sites to sterile areas. The aim of this paper was to present the local frequency of isolation and drug susceptibility of strains isolated in the period 2011-2014 from the blood of neutropenic children and to compare the susceptibility of blood isolates with the results for the colonizing flora and for strains isolated from all materials together. The aim of this study was also to specify the optimal options for empirical therapy in our center, based on the results of the susceptibility of blood-borne strains, and to estimate the suitability of antibiogram tests for colonizing flora in selecting the most probable active antibiotics to treat infections in children with hematological diseases who had negative test results of diagnostically relevant samples.

\section{Material and methods}

The analysis included the results of microbiological tests of patients hospitalized in the oncohematological wards of the Chair and Clinic of Pediatric Oncology, Hematology, and Bone Marrow Transplantation in Wrocław from 2011 to 2014. Children subjected to bone marrow stem cell transplantation were excluded from the study. The majority of the children studied had acute leukemia (60\%) with a predominance of acute lymphoblastic leukemia and lymphomas, particularly non-Hodgkin's lymphoma (15-20\%). Other markings were performed in patients with solid tumors, among which neuroblastoma, rhabdomyosarcoma, and Ewing's sarcoma prevailed. The samples for microbial diagnosis included in this research were collected in cases of suspected infections. In total, microbiological tests were conducted on 50,407 various clinical samples, including 11,468 in 2011, 12,234 in 2012, 13,762 in 2013, and 12,943 in 2014 . The largest proportion of analyzed materials in the years 2011, 2012, 2013, and 2014 were as follows: feces samples (24\%, 21\%, 23\%, and 23\%, respectively), samples from the upper respiratory tract $(24 \%, 23 \%, 23 \%$, and $23 \%$, respectively), blood $(22 \%, 21 \%, 18 \%$, and $20 \%$, respectively) and urine (16\%, 15\%, 15\%, and $16 \%$, respectively). The samples included in the research were collected in cases of suspected infections only. Microbiological diagnostics was performed at the Specialist Microbiological Laboratory of the Wroclaw Medical University Foundation. The blood cultures were processed in a Bactec 9120 (BD) using BD Bactec Peds Plus/F or BD Bactec Plus Aerobic/F and BD BactecPlus Anaerobic/F (Becton Dickinson Life Science-Diagnostic Systems). At least 2 blood samples were collected from each patient. The strains were identified using a manual system - BBL Crystal (BD) - or an automatic system - VITEK 2 (bioMerieux S.A., Marcy L'Etoile, France). The assessment of drug susceptibility and resistance mechanisms was performed in accordance with the recommendations in force during the given year, of either the Clinical and Laboratory Standards Institute (CLSI) (for the period January 1, 2011 to April 30, 2011) or of the European Committee on Antimicrobial Susceptibility Testing (EUCAST) (May 1, 2011-December 31, 2014), as well as the recommendations of the National Reference Center for Antibiotic Resistance and Surveillance (KORLD). ${ }^{7-9}$ Depending on the above-mentioned recommendations, susceptibility was tested by means of the disc diffusion method, the automatic VITEK system, and the quantitative method, using bands saturated with an antibiotic within the concentration gradient (E-tests, bioMerieux S.A., Marcy L'Etoile, France). We analyzed the positive test results of the various studied materials from 2011 to 2014 and measured the frequency of isolation of individual types of bacteria broken down into Gram-positive and Gram-negative strains. Also, drug susceptibility testing was carried out for the strains isolated in 2014 from all materials together and for only colonizing bacterial strains isolated primarily from stools and from the upper respiratory tract. A detailed assessment of the type of isolated bacteria and their susceptibility to antimicrobial agents was also conducted for the strains isolated from positive blood cultures, taking into account the dynamics of changes from year to year. In cases of repeated isolations from a single patient of the same bacteria with the same susceptibility profile, the relevant susceptibility analysis included the result for a single strain only. Coagulase-negative staphylococci were regarded as the etiological factor of bacteremia when they was isolated from at least 2 blood samples. The data was statistically analyzed with the use of STATISTICA 12.0 packages (StatSoft), in particular the significance test for the difference between 2 indices of structure (Significant Difference Test). Values of $\mathrm{p}<0.05$ were regarded as statistically significant. 


\section{Results}

Positive microbiological test results constituted a small percentage of the total number of samples collected from patients, with the majority being negative (Table 1). A particularly high percentage of negative results was obtained from blood cultures (from $86 \%$ in 2011 to as much as $91 \%$ in 2014). The number of strains from various positive samples cultured in 2011 was 1,629; in 2012, there were 2,286; in 2013 there were 2,225; and in 2014 there were 1,831 strains. Gram-positive bacteria were the predominant type in all 4 years (Table 2). A statistically significant increase in the frequency of isolation of Gram-positive bacteria was found in 2012 and 2013 compared to 2011. Coagulase-negative Staphylococcus (CNS) was decidedly the predominant group of bacteria. Gram-negative bacteria were isolated less frequently; the differences in the frequency of isolation in individual years were statistically significant only in 2012 ( $\mathrm{p}=0.0173)$. Among Gram-negative strains isolated from blood, the most frequent were Klebsiella spp. (6-11\%) and $E$. coli $(1-11 \%)$. Non-fermentative rods were isolated less frequently. The susceptibility test results of the strains isolated from blood (Table 3) show that regardless of the year, CNS strains were most susceptible to linezolid and vancomycin (96-100\%) and to teicoplanin (82-96\%), with MRCNS (methicillin-resistant CNS) accounting for $77-86 \%$. They were least susceptible to macrolides and, additionally, a statistically significant drop in susceptibility to these drugs was observed, from $31 \%$ in 2011 to $4 \%$ in 2014 ( $\mathrm{p}=0.0001)$. The drug susceptibility of $S$. aureus and Enterococcus spp. is difficult to assess due to the low occurrence of this strain. However, it was found that all $S$. aureus strains were susceptible to glycopeptides, and linezolid and Enterococcus spp. were susceptible to linezolid. Additionally, 100\% of the enterococci isolated in 2013 and 2014 were susceptible to glycopeptides. Apart from the year 2014 ( $\mathrm{p}=0.0013$ ), MRSA strains (methicillinresistant $S$. aureus) were not isolated. The susceptibility of Gram-negative bacilli isolated from blood is presented in Table 4. All of the Enterobacteriaceae strains (100\%)

Table 1. The ratio of negative results of microbiological culture over 4 years

\begin{tabular}{|c|c|c|c|c|c|c|c|c|}
\hline \multirow{3}{*}{ Year } & \multicolumn{8}{|c|}{ Examined samples } \\
\hline & \multicolumn{2}{|r|}{ all } & \multicolumn{2}{|r|}{ blood } & \multicolumn{2}{|r|}{ urine } & \multicolumn{2}{|c|}{ from lower respiratory tract } \\
\hline & $\mathrm{n}$ & negative results, n (\%) & $\mathrm{n}$ & negative results, n (\%) & $\mathrm{n}$ & negative results, n (\%) & $\mathrm{n}$ & negative results, n (\%) \\
\hline 2011 & 11,468 & $6666(58)$ & 2500 & $2146(86)$ & 986 & $508(52)$ & 49 & $10(20)$ \\
\hline 2012 & 12,234 & $8372(68)$ & 2568 & $2268(88)$ & 1000 & $510(51)$ & 24 & $9(38)$ \\
\hline 2013 & 13,762 & $8980(65)$ & 2526 & $2283(90)$ & 1095 & $602(55)$ & 33 & $8(24)$ \\
\hline 2014 & 12,943 & $9180(71)$ & 2565 & $2333(91)$ & 1108 & $514(46)$ & 21 & $6(29)$ \\
\hline
\end{tabular}

Table 2. Frequency of isolation of bacterial strains from blood

\begin{tabular}{|c|c|c|c|c|c|c|c|c|}
\hline \multirow{2}{*}{$\frac{\text { Year }}{\text { Bacterial strains }}$} & \multicolumn{2}{|c|}{2011} & \multicolumn{2}{|c|}{2012} & \multicolumn{2}{|c|}{2013} & \multicolumn{2}{|c|}{2014} \\
\hline & $\mathrm{n}$ & $\%$ & $n$ & $\%$ & $\mathrm{n}$ & $\%$ & $\mathrm{n}$ & $\%$ \\
\hline Gram-positive & $167^{A}$ & 60 & $196^{\mathrm{B}}$ & 70 & $155^{C}$ & 67 & $140^{\mathrm{D}}$ & 63 \\
\hline CNS & 113 & 41 & 132 & 47 & 107 & 47 & 105 & 47 \\
\hline Enterococcus spp. & 28 & 10 & 15 & 5 & 10 & 4 & 6 & 3 \\
\hline S. aureus & 3 & 1 & 19 & 7 & 5 & 2 & 16 & 7 \\
\hline Steptococcus orale gr. & 16 & 6 & 12 & 4 & 11 & 5 & 12 & 5 \\
\hline other Gram-positive & 7 & 2 & 18 & 6 & 22 & 9 & 1 & $<1$ \\
\hline Gram-negative & $112^{\mathrm{E}}$ & 40 & $86^{\mathrm{F}}$ & 30 & $78^{\mathrm{G}}$ & 33 & $82^{\mathrm{H}}$ & 37 \\
\hline Enterobacteriaceae & 73 & 26 & 49 & 17 & 56 & 24 & 58 & 26 \\
\hline E. coli & 17 & 6 & 30 & 11 & 15 & 6 & 21 & 9 \\
\hline Klebsiella spp. & 30 & 11 & 4 & 1 & 16 & 7 & 16 & 7 \\
\hline Enterobacter spp. & 10 & 4 & 15 & 5 & 9 & 4 & 15 & 7 \\
\hline other Enterobacteriaceae & 16 & 5 & 0 & 0 & 16 & 7 & 6 & 3 \\
\hline Non-fermentative rods & 39 & 14 & 37 & 13 & 22 & 9 & 24 & 11 \\
\hline Acinetobacter spp. & 10 & 4 & 25 & 9 & 8 & 3 & 4 & 2 \\
\hline Pseudomonas aeruginosa & 14 & 5 & 10 & 4 & 14 & 6 & 12 & 5 \\
\hline other non-fermentative rods & 15 & 5 & 2 & $<1$ & 0 & 0 & 8 & 4 \\
\hline Total & 279 & 100 & 282 & 100 & 233 & 100 & 222 & 100 \\
\hline
\end{tabular}

CNS - coagulase-negative Staphylococcus; $n$ - number of isolated strains; $p<0.05\left({ }^{B / A} p=0.009,{ }^{C / A} p=0.0145,{ }^{F / E} p=0.0173\right) ; p>0.05\left({ }^{D / A},{ }^{G / E}, H / E\right)$. 
Table 3. Drug susceptibility patterns of Gram-positive bacterial strains isolated from blood from children in the oncohematological ward

\begin{tabular}{|c|c|c|c|c|c|c|c|c|c|}
\hline \multirow{2}{*}{$\begin{array}{l}\text { Gram-positive } \\
\text { bacterial strains }\end{array}$} & \multicolumn{2}{|c|}{$2011^{A}$} & \multicolumn{2}{|c|}{2012} & \multicolumn{2}{|c|}{2013} & \multicolumn{2}{|c|}{$2014^{\mathrm{B}}$} & \multirow{2}{*}{$p B / A$} \\
\hline & $\mathrm{n}$ & $\%$ & $\mathrm{n}$ & $\%$ & $\mathrm{n}$ & $\%$ & $\mathrm{n}$ & $\%$ & \\
\hline \multicolumn{10}{|c|}{ Coagulase-negative Staphycococcus } \\
\hline Cefoxitin & 93 & 23 & 94 & 18 & 97 & 14 & 87 & 18 & ns \\
\hline Erythromycin & 36 & 31 & 79 & 24 & 94 & 9 & 72 & 4 & 0.0001 \\
\hline Clindamycin & 35 & 63 & 77 & 47 & 91 & 52 & 72 & 36 & 0.0089 \\
\hline Gentamicin & 81 & 44 & 94 & 43 & 97 & 52 & 87 & 53 & ns \\
\hline Co-trimoxazole & 91 & 23 & 91 & 13 & 97 & 20 & 86 & 19 & ns \\
\hline Doxycycline & 77 & 65 & 89 & 76 & 96 & 71 & 86 & 58 & ns \\
\hline Vancomycin & 91 & 100 & 94 & 100 & 95 & 96 & 85 & 100 & ns \\
\hline Teicoplanin & 93 & 87 & 93 & 82 & 93 & 95 & 85 & 96 & 0.024 \\
\hline Linezolid & 91 & 100 & 93 & 98 & 95 & 96 & 87 & 100 & ns \\
\hline \multicolumn{10}{|c|}{ S. aureus } \\
\hline Cefoxitin & 3 & 100 & 10 & 100 & 4 & 100 & 12 & 92 & 0.0013 \\
\hline Erythromycin & 3 & 67 & 9 & 56 & 4 & 100 & 10 & 80 & ns \\
\hline Clindamycin & 3 & 67 & 9 & 67 & 4 & 100 & 10 & 90 & ns \\
\hline Gentamicin & 3 & 67 & 10 & 90 & 4 & 100 & 12 & 92 & ns \\
\hline Co-trimoxazole & 3 & 100 & 10 & 80 & 4 & 100 & 11 & 100 & ns \\
\hline Doxycycline & 2 & 100 & 10 & 90 & 4 & 100 & 12 & 100 & ns \\
\hline Vancomycin & 3 & 100 & 10 & 100 & 4 & 100 & 12 & 100 & ns \\
\hline Teicoplanin & 3 & 100 & 9 & 100 & 4 & 100 & 11 & 100 & ns \\
\hline Linezolid & 3 & 100 & 10 & 100 & 4 & 100 & 12 & 100 & ns \\
\hline \multicolumn{10}{|c|}{ Enterococcus spp. } \\
\hline Ampicillin & 18 & 11 & 11 & 64 & 6 & 16 & 6 & 0 & ns \\
\hline Gentamicin high concent & 10 & 70 & 11 & 73 & 8 & 88 & 6 & 33 & ns \\
\hline Streptomycin high concent & 11 & 82 & 11 & 45 & 8 & 50 & 6 & 33 & 0.0456 \\
\hline Vancomycin & 17 & 82 & 11 & 55 & 8 & 100 & 6 & 100 & ns \\
\hline Teicoplanin & 18 & 100 & 11 & 64 & 8 & 100 & 6 & 100 & ns \\
\hline Linezolid & 18 & 100 & 11 & 100 & 8 & 100 & 6 & 100 & ns \\
\hline
\end{tabular}

p B/A - significance test result for the difference in antibiotic susceptibility between 2014 (B) and 2011 (A); n - number examined; \% - percent of susceptibility; ns - not statistically significant.

were susceptible to imipenem and meropenem, apart from the year 2014 (with 9\% resistant strains) ( $>0.05$ ). Susceptibility to ertapenem was lower and it stood at $80 \%$ in 2014 ( $\mathrm{p}>0.05)$. Apart from carbapenems, intestinal rods were most susceptible to amikacin (77-93\%). The non-fermentative rods isolated in 2013 and 2014 were less susceptible to imipenem and meropenem, at $71 \%$ for both antibiotics in 2013 , and $67 \%$ and $71 \%$, respectively, in 2014 . The decrease in susceptibility to carbapenems was statistically significant in 2014 ( $\mathrm{p}=0.0307)$.

The study also included a comparison of the drug susceptibility of strains isolated from blood with those reported as a colonizing flora and with bacterial strains isolated from all the materials together. It was found that compared to the total number of investigated strains and to those isolated as colonizing flora, CNS isolated from blood were nearly twice as frequently resistant ( $\mathrm{p}<0.05)$ to cefoxitin (MRCNS). The same strains were also statistically significantly more susceptible to gentamicin in comparison to colonizing bacteria (Fig. 1). Furthermore, Enterobacteriaceae isolated from blood were more frequently resistant to antimicrobials than the other 2 compared groups. They were especially statistically significantly resistant to carbapenems and ceftazidime (Fig. 2). Different data were obtained for Gram-negative non-fermenters (NF), a statistically significant higher percentage of which was susceptible to half of the analyzed antibiotics (piperacillin/tazobactam, ceftazidime, cefepime, doripenem, gentamicin, and ciprofloxacin) among blood isolates in comparison with the colonizing strains (Fig. 3). Gram-negative non-fermenters were more resistant only to imipenem, but the differences were not statistically significant $(\mathrm{p}=0.0721)$. Table 5 presents the frequency of isolation of bacteria with specified resistance phenotypes. These data also confirm that the blood-borne staphylococci, enterococci, and Enterobacteriaceae were resistant to methicillin and to high concentrations of aminoglycosides and that they produced extended-spectrum beta-lactamases (ESBL) more often than the bacteria isolated from all materials. 
Table 4. Drug susceptibility patterns of Gram-negative bacterial strains isolated from blood from children in the oncohematological ward

\begin{tabular}{|c|c|c|c|c|c|c|c|c|c|}
\hline \multirow{2}{*}{$\begin{array}{l}\text { Gram-negative } \\
\text { bacterial strains }\end{array}$} & \multicolumn{2}{|c|}{$2011^{A}$} & \multicolumn{2}{|c|}{2012} & \multicolumn{2}{|c|}{2013} & \multicolumn{2}{|c|}{$2014^{B}$} & \multirow{2}{*}{$\mathrm{p} \mathrm{B} / \mathrm{A}$} \\
\hline & $\mathrm{n}$ & $\%$ & $\mathrm{n}$ & $\%$ & $\mathrm{n}$ & $\%$ & $\mathrm{n}$ & $\%$ & \\
\hline \multicolumn{10}{|c|}{ Enterobacteriaceae } \\
\hline Piperacillin/tazobactam & 35 & 69 & 27 & 70 & 48 & 85 & 45 & 62 & ns \\
\hline Cefotaxime & 35 & 71 & 27 & 81 & 48 & 79 & 44 & 55 & ns \\
\hline Ceftazidime & 35 & 71 & 27 & 85 & 48 & 79 & 44 & 55 & ns \\
\hline Cefepime & 32 & 75 & 27 & 89 & 48 & 85 & 45 & 67 & ns \\
\hline Aztreonam & 32 & 69 & 27 & 89 & 48 & 81 & 39 & 51 & ns \\
\hline Imipenem & 36 & 100 & 27 & 100 & 48 & 100 & 45 & 91 & ns \\
\hline Meropenem & 36 & 100 & 27 & 100 & 48 & 100 & 45 & 91 & ns \\
\hline Doripenem & 35 & 94 & 27 & 100 & 48 & 100 & 42 & 90 & ns \\
\hline Ertapenem & 35 & 91 & 27 & 100 & 48 & 100 & 45 & 80 & ns \\
\hline Gentamicin & 36 & 64 & 27 & 74 & 48 & 77 & 45 & 62 & ns \\
\hline Amikacin & 36 & 83 & 27 & 93 & 48 & 79 & 45 & 77 & ns \\
\hline Tobramycin & 22 & 47 & 20 & 70 & 48 & 71 & 45 & 68 & ns \\
\hline Co-trimoxazole & 35 & 37 & 27 & 26 & 48 & 56 & 45 & 18 & ns \\
\hline Ciprofloxacin & 32 & 50 & 27 & 59 & 48 & 79 & 45 & 60 & ns \\
\hline Colistin & 6 & 100 & 0 & 0 & 0 & 0 & 17 & 100 & ns \\
\hline \multicolumn{10}{|c|}{ Non-fermentative rods } \\
\hline Piperacillin/tazobactam & 8 & 100 & 6 & 100 & 14 & 71 & 13 & 85 & ns \\
\hline Ceftazidime & 8 & 75 & 7 & 86 & 14 & 86 & 14 & 93 & ns \\
\hline Cefepime & 4 & 100 & 7 & 86 & 13 & 100 & 14 & 93 & ns \\
\hline Aztreonam & 7 & 86 & 5 & 40 & 15 & 33 & 7 & 29 & 0.0309 \\
\hline Imipenem & 14 & 100 & 10 & 70 & 21 & 71 & 14 & 71 & 0.0307 \\
\hline Meropenem & 14 & 100 & 10 & 80 & $21^{\circ}$ & 67 & 14 & 71 & 0.0307 \\
\hline Doripenem & 11 & 100 & 10 & 80 & 21 & 71 & 12 & 100 & ns \\
\hline Gentamicin & 14 & 86 & 10 & 70 & 21 & 100 & 14 & 100 & ns \\
\hline Amikacin & 14 & 86 & 10 & 70 & 21 & 90 & 14 & 93 & ns \\
\hline Tobramycin & 12 & 83 & 10 & 70 & 21 & 86 & 14 & 100 & ns \\
\hline Ciprofloxacin & 13 & 85 & 10 & 60 & 21 & 86 & 14 & 100 & ns \\
\hline Colistin & 3 & 100 & 3 & 100 & 4 & 25 & 7 & 100 & ns \\
\hline
\end{tabular}

p B/A - significance test result for the difference in antibiotic susceptibility between 2014 (B) and 2011 (A); n - number examined; \% - percent of susceptibility; ns - not statistically significant.

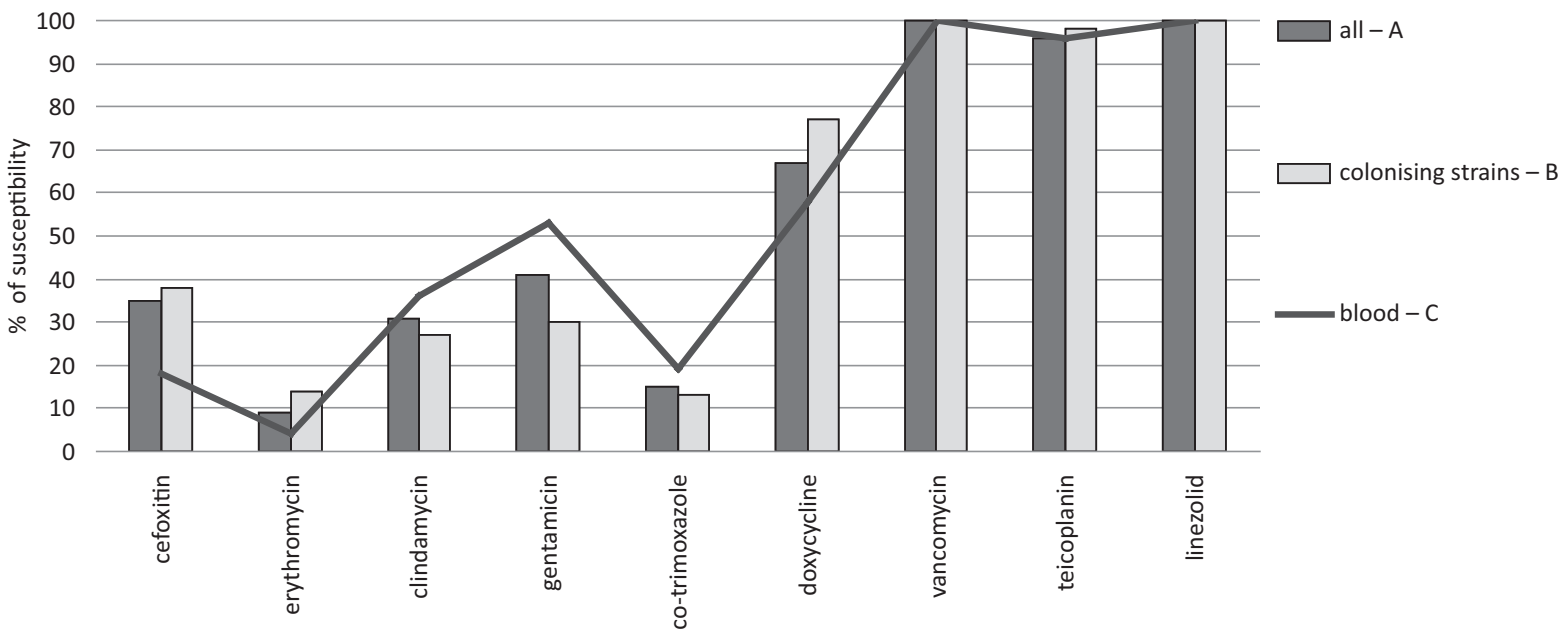

Fig. 1. Comparison of antibiotic susceptibility (\%) of CNS strains isolated from blood, from all materials and for colonising strains in 2014

$C / A p<0.05$ for cefoxitin ( $p=0.0024)$; C/A for other antibiotics $p>0.05 ; C / B p<0.05$ for cefoxitin $(p=0.007)$, erythromycin ( $p=0.0434)$, gentamicin $(p=0.0037)$, doxycycline $(p=0.0093) ; C / B$ for other antibiotics $p>0.05$. 


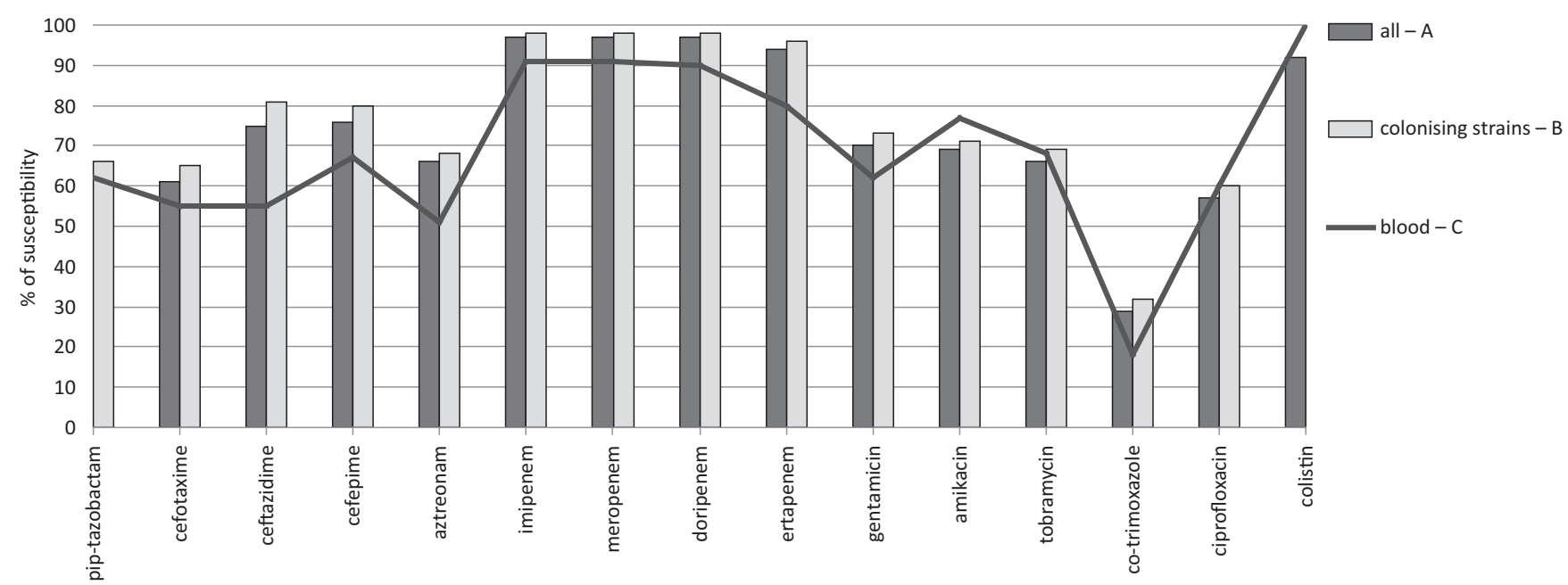

Fig. 2. Comparison of antibiotic susceptibility (\%) of Enterobacteriaceae strains isolated from blood, from all materials and for colonising strains in 2014

$C / A p<0.05$ for ceftazidime $(p=0.021)$, imipenem $(p=0.0162)$, meropenem $(p=0.0164)$, doripenem $(p=0.0086)$, ertapenem $(p=0.0001)$, for other $C / A$ $p>0.05 ; C / B p<0.05$ for ceftazidime $(p=0)$, cefepime $(p=0.0272)$, aztreonam $(p=0.0276)$, imipenem $(p=0.0006)$, meropenem $(p=0.0041)$, doripenem $(p=0.0005)$, ertapenem $(p=0)$, co-trimoxazole $(p=0.0439)$, for other $C / B p>0.05$.

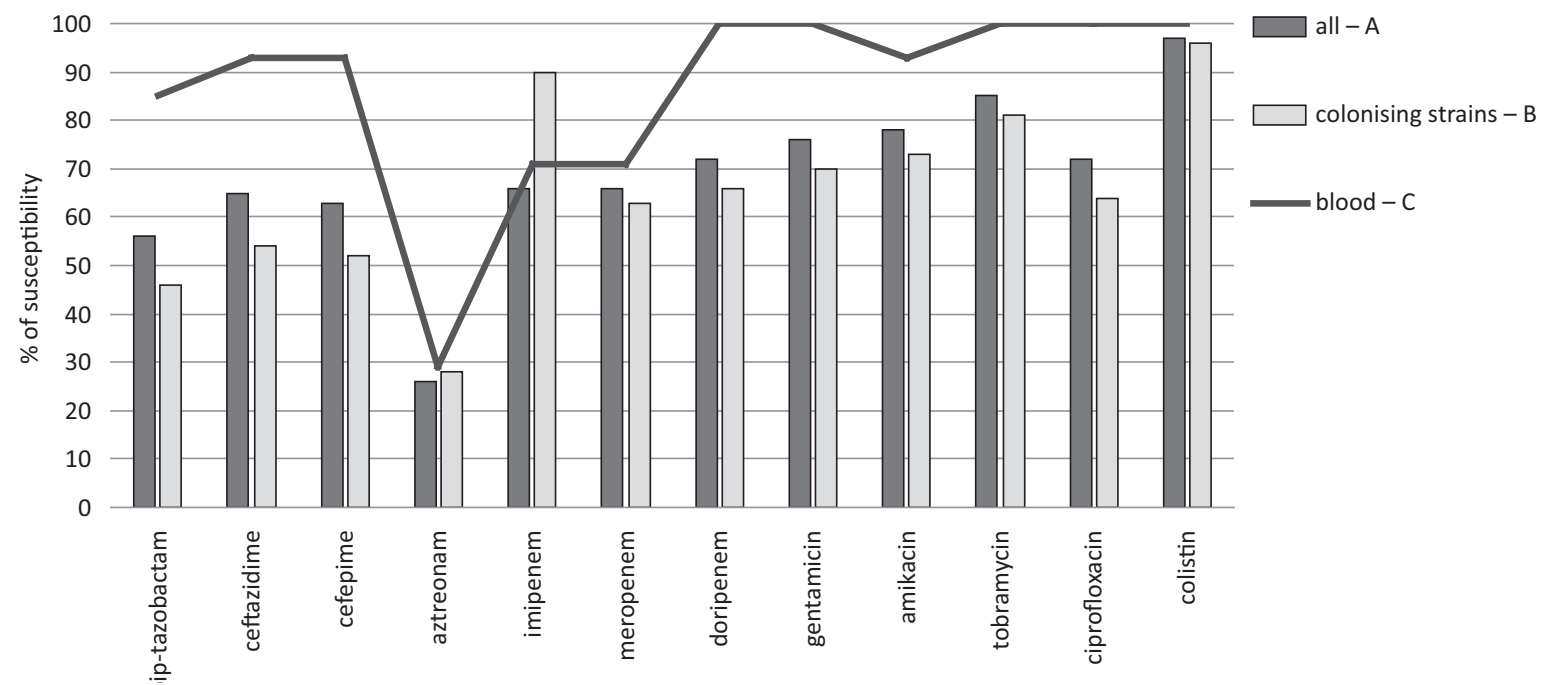

Fig. 3. Comparison of antibiotic susceptibility (\%) of non-fermentative rods isolated from blood, from all materials and for colonising strains in 2014

$C / A p<0.05$ for ceftazidime $(p=0.0398)$, cefepime $(p=0.0317)$, doripenem $(p=0.0341)$, gentamicin $(p=0.0422)$, for other $C / A p>0.05 ; C / B p<0.05$ for piperacillin/tazobactam $(p=0.0129)$, ceftazidime $(p=0.0087)$, cefepime $(p=0.0061)$, doripenem $(p=0.0162)$, gentamicin $(p=0.0173)$, ciprofloxacin $(p=0.0082)$, for other $C / B p>0.05$.

\section{Discussion}

Blood is the most valuable material for the purposes of microbiological diagnosis of infections in hematological patients. It plays a significant role not only in the diagnosis of sepsis, but also in organ infections, where the bacteria enter the bloodstream in the majority of cases. At the same time, it becomes challenging to determine the location of the infection due to neutropenia and the lack of evident clinical symptoms. Unfortunately, blood is also one of the most difficult materials to culture microorganisms in, especially in patients who previously received antibiotic prophylaxis. ${ }^{1,10}$ Numerous studies confirm the difficulties encountered in blood diagnostics and suggest that positive results of blood cultures may be obtained in only $11-30 \%$ of cases. ${ }^{10-14}$ During our own studies conducted over a period of 4 years, we had an average of $11 \%$ of positive blood cultures. Such a small percentage of positive cultures may be due to a number of factors, including blood collection coinciding with antibiotic treatment and non-compliance with the procedures concerning blood collection for culture. ${ }^{5}$ It also shows the need to actively monitor microbiological diagnostic procedures, especially of mistakes relating to collecting blood for culture from oncohematological pediatric patients. Another reason for the reduced frequency of isolating bacteria from blood is the fact that microbiological tests are performed in all febrile neutropenic patients. Although bacterial infections are responsible for a large number of febrile episodes in this group of patients, in some of them their cause is different, for example, a neoplastic disease, chemotherapy, blood product transfusion, or a viral or fungal infection. The low 
Table 5. Mechanism of resistance of strains identified in 2014

\begin{tabular}{|c|c|c|c|c|c|c|c|c|c|c|}
\hline \multirow{3}{*}{$\begin{array}{l}\text { Phenotyp } \\
\text { of resistance }\end{array}$} & \multicolumn{10}{|c|}{ Frequency of isolation } \\
\hline & \multicolumn{2}{|c|}{ all materials } & \multicolumn{2}{|c|}{ blood } & \multicolumn{2}{|c|}{ urine } & \multicolumn{2}{|c|}{$\begin{array}{l}\text { from lower } \\
\text { respiratory tract }\end{array}$} & \multicolumn{2}{|c|}{ colonising flora* } \\
\hline & $\mathrm{N}$ & $\mathrm{n} / \%$ & $\mathrm{~N}$ & $\mathrm{n} / \%$ & $\mathrm{~N}$ & $\mathrm{n} / \%$ & $\mathrm{~N}$ & $\mathrm{n} / \%$ & $\mathrm{~N}$ & $\mathrm{n} / \%$ \\
\hline \multicolumn{11}{|c|}{ Gram-positive } \\
\hline $\begin{array}{l}\text { Staphylococcus spp. } \\
\text { MRSA } \\
\text { MRCNS }\end{array}$ & $\begin{array}{r}35 \\
451\end{array}$ & $\begin{array}{c}2 / 6 \\
293 / 65\end{array}$ & $\begin{array}{l}16 \\
87\end{array}$ & $\begin{array}{c}2 / 13 \\
71 / 82\end{array}$ & $\begin{array}{r}1 \\
109\end{array}$ & $\begin{array}{c}0 \\
84 / 77\end{array}$ & $\begin{array}{l}0 \\
2\end{array}$ & $\begin{array}{l}0 \\
0\end{array}$ & $\begin{array}{r}18 \\
187\end{array}$ & $\begin{array}{c}0 \\
144 / 62\end{array}$ \\
\hline $\begin{array}{l}\text { Enterococcus spp. } \\
\text { HLAR } \\
\text { VRE or GRE }\end{array}$ & $\begin{array}{l}1512 \\
1501\end{array}$ & $\begin{array}{l}941 / 62 \\
283 / 19\end{array}$ & $\begin{array}{l}6 \\
6\end{array}$ & $\begin{array}{c}4 / 67 \\
0\end{array}$ & $\begin{array}{l}235 \\
235\end{array}$ & $\begin{array}{l}20 / 9 \\
20 / 9\end{array}$ & $\begin{array}{l}2 \\
2\end{array}$ & $\begin{array}{l}0 \\
0\end{array}$ & $\begin{array}{l}1265 \\
1265\end{array}$ & $\begin{array}{l}917 / 72 \\
263 / 19\end{array}$ \\
\hline \multicolumn{11}{|c|}{ Gram-negative } \\
\hline $\begin{array}{l}\text { Enterobacteriaceae } \\
\text { ESBL } \\
\text { MBL }\end{array}$ & $\begin{array}{l}1080 \\
1080\end{array}$ & $\begin{array}{c}195 / 18 \\
6 /<1\end{array}$ & $\begin{array}{l}45 \\
45\end{array}$ & $\begin{array}{c}19 / 42 \\
0\end{array}$ & $\begin{array}{l}149 \\
149\end{array}$ & $\begin{array}{c}32 / 22 \\
1 /<1\end{array}$ & $\begin{array}{l}3 \\
3\end{array}$ & $\begin{array}{c}3 / 100 \\
0\end{array}$ & $\begin{array}{l}878 \\
878\end{array}$ & $\begin{array}{l}141 / 16 \\
5 /<1\end{array}$ \\
\hline $\begin{array}{l}\text { P. aeruginosa } \\
\text { MBL }\end{array}$ & 30 & $7 / 23$ & 12 & 0 & 3 & 0 & 2 & 0 & 22 & $7 / 32$ \\
\hline
\end{tabular}

* mainly strains from stools and the upper respiratory tract; $\mathrm{N}$ - number of examined strains; $\mathrm{n}$ - number of strains with a particular mechanism of resistance; \% - percent of resistance; MRSA - methicillin-resistant Staphylococcus aureus; MRCNS - methicillin-resistant coagulase-negative Staphylococcus; HLAR - high-level aminoglycoside resistance; VRE - vancomycin-resistant Enterococcus, GRE - glycopeptide-resistant Enterococcus; ESBL - extended spectrum beta-lactamases; MBL - metallo-beta-lactamases.

detection rates of bacteria in blood as well as the risk of a fast-developing infection from a previous colonization are 2 reasons why in oncohematological neutropenic patients, colonizing bacteria from stools or from the upper respiratory tract are more frequently diagnosed microbiologically than in other patients. The results of the above tests are valuable as they allow us to monitor multi-resistance. ${ }^{1,15}$ In the case of oncohematological patients, knowledge about the resistance profile of the colonizing flora can be used in the selection of an adequate antibiotic therapy at the time of onset of the infection and before test results become available. ${ }^{5,16}$ Additionally, it can serve as valuable information for Nosocomial Infection Surveillance Teams, which, in the case of isolating alert pathogens, can initiate efforts to prevent the relevant strains from spreading further. Multi-resistance increases the virulence potential of pathogens and is the reason why such strains are more frequently found in invasive infections. This process also reduces the chances for effective treatment. ${ }^{1}$ This claim was confirmed by the results of our research, where both MRCNS strains and ESBL-positive Enterobacteriaceae and Enterococcus with the HLAR phenotype were more frequently isolated from blood than from other materials. On the other hand, the fact that CNS strains and Enterobacteriaceae isolated from blood showed a higher resistance to antibiotics than the colonizing flora may indicate an exogenous origin of the bacterial strains; however, this supposition cannot be proven due to a lack of genetic studies. Future introduction of genetic studies which would examine the similarities between strains isolated from the blood and colonizing flora could help assess the usefulness of monitoring the susceptibility of colonizing flora when selecting effective treatment options at the time of infection. In accordance with the data presented by Mikulska et al., the percentage of strains isolated from the blood of hematological pediatric patients was smaller than in our research, which for MRSA was from 0 to $26 \%$, for MRCNS was 38-39\%, and for ESBL was 18\%. ${ }^{17}$ According to Mikulska et al., the significantly higher percentage of resistant strains found in our study (the $82 \%$ of MRCNS and the $42 \%$ of ESBL, in particular) is more characteristic of adult patients. ${ }^{17}$ However, data presented by other authors, including Al-Mulla et al. from Qatar confirm a high percentage of MRCNS strains (from $78 \%$ to $100 \%) .{ }^{18}$ Similar data were reported by Lv et al. from China showing $73-100 \%$ of MRCNS strains. ${ }^{19}$ In general, literature data most often show the prevalence of Gram-positive over Gram-negative bacteria among blood isolates, ${ }^{17,20-23}$ which is in line with the results of our own research conducted from 2011 to 2014 (63-70\% vs 30-40\%). The previous study from 2001-2002 from the same clinic showed a greater number of Gram-negative than Gram-positive bacteria (56\% vs $44 \%$ ) isolated from blood. ${ }^{20}$ Currently, there are reports indicating the predominance of Gram-negative microorganisms. ${ }^{11,12,17,24}$ Mikulska et al. noted a predominance of Enterobacteriaceae in 5 out of the 12 analyzed research studies. ${ }^{17}$ On the basis of reports from various centers, she also noted the growing role of Enterococcus spp. and Enterobacteriaceae and the decreasing role of $P$. aeruginosa. No similar tendency was observed in our study. On the contrary, the percentage of isolation of enterococci in 2014 declined by $7 \%$ in comparison with 2011 and no differences were found in the consecutive years of the study with respect to other types of bacteria. Despite the fact that CNS strains are predominant among blood isolates, they do not pose such a threat to patients' lives as 
Enterobacteriaceae or non-fermenters. They have at their disposal not only a huge arsenal of various virulence factors, but also the ability to develop resistance to the majority of antibiotics. ${ }^{24}$ In accordance with American recommendations regarding the protocol in cases of neutropenic fever in oncological pediatric patients and/or patients subjected to transplantations of hematopoietic stem cells, given the high risk of infectious complications, initial empirical therapy should account for the administration of an antibiotic active against Gram-negative bacilli, including $P$. aeruginosa..$^{5}$ Among the antibiotics recommended in monotherapy are piperacillin/tazobactam, ticarcillin/clavulanic acid, cefepim, ceftazidime and meropenem, or imipenem. ${ }^{5}$ The choice of an antibiotic is better when it is based on knowledge of the local epidemiological situation. Thus, it seems that - in line with our microbiological analysis of local epidemiological situation - our pediatric ward might use piperacillin/tazobactam or cefepime (which additionally would be a carbapenemsaving strategy) for the initial therapy. For patients suffering from acute myeloid leukemia with no symptoms of infection but with a high risk of infection complications, oral chemoprophylaxis with the use of fluoroquinolone may be the recommended option. ${ }^{1}$ Although fluoroquinolones have been reported as an important option in the prevention of infection, there are a number of controversies associated with this group. ${ }^{1,25,26}$ On the one hand, there are reports confirming the role of antibiotic prophylaxis in reducing the risk of infection with Gram-negative bacilli; on the other hand, growing levels of resistance to fluoroquinolones have unfortunately been reported. ${ }^{25-28}$ However, in our research no negative changes in the susceptibility to ciprofloxacin were observed among the Gram-negative bacilli isolated from blood. Nevertheless, in comparison with the results of studies conducted from 2001 to 2002 at the same center, there has been a visible increase (by 20\%) in resistance to fluoroquinolones. ${ }^{20}$ The susceptibility of Gram-negative bacilli to other antibiotics was varied. In 2014, apart from carbapenems and colistin, Enterobacteriaceae strains remained most susceptible to amikacin (77\%), but there has been an increase in resistance to this antibiotic as well. Fewer strains were susceptible to gentamicin and tobramycin. However, in 2014 there were as many as $21 \%$ more strains susceptible to tobramycin than in 2011. In their study of pediatric patients, Aslan et al. reported that only $7.7 \%$ of $E$. coli were susceptible to amikacin and $69.2 \%$ were susceptible to gentamicin, while Lv et al. reported $91.7 \%$ and $16.7 \%$, respectively. ${ }^{19,29}$ In our own research, tobramycin was $100 \%$ active in vitro against non-fermenters and, additionally, $7 \%$ more active than amikacin. Thus, it may serve as an alternative to amikacin, which is generally used in combined therapy, especially against such strains as $P$. aeruginosa. Lv et al. reported that more strains were susceptible to gentamicin than to amikacin among $P$. aeruginosa ${ }^{19}$ In general, however, susceptibility to individual aminoglycoside agents is very diversified across the centers conducting the studies, which was clearly demonstrated by Trecarichi and Tumbarello. ${ }^{30}$

In summary, our study included only one center, so the achieved results and conclusions may have some limitations and may reflect only local trends. Over the 4 years of our research, a growing drug resistance was observed among the Enterobacteriaceae bacilli, with no such trend among non-fermenters. However, in the case of the latter ones, many more strains have been observed to be resistant to carbapenems than to other studied antibiotics. The problem of growing drug resistance among nosocomial strains is also reflected by the isolation from blood of a methicillin-resistant $S$. aureus strain for the $1^{\text {st }}$ time in 2014. The results of the sensitivity of Gram-negative bacteria from blood indicate that, apart from carbapenems, the strains were most susceptible to piperacillin/tazobactam, cefepime, and aminoglycosides. In our Wrocław center, it has also been shown that CNS and Enterobacteriaceae strains isolated from blood were statistically significantly less susceptible to antibiotics than colonizing flora.

\section{Conclusions}

Our results show that the choice of appropriate antibiotics for the treatment of infections in children from the studied hematological ward based on antibiograms for colonizing flora may be difficult because there is a risk that the antibiograms do not take into account the more resistant strains. According to the antibiotic susceptibility of the examined strains isolated from blood, the most probable active empirical and carbapenem-saving therapy could be conducted with piperacillin/tazobactam or cefepime.

\section{References}

1. Gustinetti G, Mikulska M. Bloodstream infections in neutropenic cancer patients: A practical update. Virulence. 2016;7(3):280-297. doi: 10.1080/21505594.2016.1156821

2. Skovbjerg S, Welinder-Olsson $\mathrm{C}$, Kondori N, et al. Optimization of the detection of microbes in blood from immunocompromised patients with haematological malignancies. Clin Microbiol Infect. 2009;15(7): 680-683.

3. Xu J, Moore JE, Millar BC, et al. Improved laboratory diagnosis of bacterial and fungal infections in patients with hematological malignancies using PCR and ribosomal RNA sequence analysis. Leuk Lymphoma. 2004;45:1637-1641.

4. Mancini N, Clerici D, Diotti R, et al. Molecular diagnosis of sepsis in neutropenic patients with haematological malignancies. J Med Microbiol. 2008;57:601-604.

5. Lehrnbecher T, Phillips R, Alexander S, et al. Guideline for the management of fever and neutropenia in children with cancer and/or undergoing hematopoietic stem-cell transplantation. J Clin Oncol. 2012;30(35):4427-4438.

6. Oliver JD. Recent findings on the viable but nonculturable state in pathogenic bacteria. FEMS Microbiol Rev. 2010;34(4):415-425. doi: 10.1111/j.1574-6976.2009.00200

7. Clinical and Laboratory Standards Institute. Performance Standards for Antimicrobial Susceptibility Testing. CLSI ; Twenty-First Informational Supplement. CLSI document M100-S21. Clinical and Laboratory Standards Institute, Wayne, PA, 2011. 
8. The European Committee on Antimicrobial Susceptibility Testing - EUCAST. Clinical breakpoints v. 1.3, v.2, v.3.1, v.4. http://www.eucast. org/ast_of_bacteria/previous_versions_of_documents/. Accessed January 6, 2014.

9. Krajowy Ośrodek Referencyjny ds. Lekowrażliwości Drobnoustrojów - KORLD. http://www.korld.edu.pl/spec_rekomendacje.php. Accessed April 10, 2013.

10. Gaytán-Martínez J, Mateos-García E, Sánchez-Cortés E, GonzálezLlaven J, Casanova-Cardiel LJ, Fuentes-Allen JL. Microbiological findings in febrile neutropenia. Arch Med Res. 2000;31:388-392.

11. Asturias EJ, Corral JE, Quezada J. Evaluation of six risk factors for the development of bacteremia in children with cancer and febrile neutropenia. Curr Oncol. 2010;17(2):59-63.

12. Greenberg D, Moser A, Yagupsky P, et al. Microbiological spectrum and susceptibility patterns of pathogens causing bacteraemia in paediatric febrile neutropenic oncology patients: comparison between two consecutive time periods with use of different antibiotic treatment protocols. Int J Antimicrob Agents. 2005;25:469-473.

13. Duncan C, Chisholm JC, Freeman S, Riley U, Sharland M, Pritchard Jones K. A prospective study of admissions for febrile neutropenia in secondary paediatric units in South East England. Pediatr Blood Cancer. 2007;49:678-681.

14. Koivula I, Hämäläinen S, Jantunen E, et al. Elevated procalcitonin predicts Gram-negative sepsis in haematological patients with febrile neutropenia. Scand J Infect Dis. 2011;43(6-7):471-478. doi: 10.3109/ 00365548.2011 .554855

15. Carlet J. The gut is the epicentre of antibiotic resistance. Antimicrob Resist Infect Control. 2012;1(1):1-7.

16. Szmyd K, Wróbel G, Węcławek-Tompol J, Wójcik D, Dobaczewski G, Chybicka A. Czynniki ryzyka wystąpienia zakażenia krwi u dzieci z upośledzoną odpornością. Adv Clin Exp Med. 2004;13(4):575-580.

17. Mikulska M, Viscoli $C$, Orasch $C$, et al. Aetiology and resistance in bacteraemias among adult and paediatric haematology and cancer patients. J Infect. 2014;68(4):321-331.

18. Al-Mulla NA, Taj-Aldeen SJ, El Shafie S, Janahi M, Al-Nasser AA, Chandra P. Bacterial bloodstream infections and antimicrobial susceptibility pattern in pediatric hematology/oncology patients after anticancer chemotherapy. Infect Drug Resist. 2014;7:289-299.

19. Lv H, Ning BT, Wu XY, et al. Clinical features of bloodstream infection in children with haematological malignancies. Hong Kong J Paediatr. 2013;18(1):12-18.
20. Kowalska-Krochmal B, Dolna I, Ruczkowska J, et al. Częstość izolacji i wrażliwość na antybiotyki bakterii od dzieci z oddziału hematologii (Wrocław, 1999-2000 vs 2001-2002). Adv Clin Exp Med. 2004;13(2): 215-226.

21. Castagnola E, Rossi MR, Cesaro S, et al. Incidence of bacteremias and invasive mycoses in children with acute non-lymphoblastic leukemia: Results from a multi-center Italian study. Pediatr Blood Cancer. 2010;55:1103-1107.

22. Simon A, Ammann RA, Bode U, et al. Healthcare-associated infections in pediatric cancer patients: Results of a prospective surveillance study from university hospitals in Germany and Switzerland. BMC Infect Dis. 2008;8:70-79.

23. Nørgaard M. Risk of infections in adult patients with haematological malignancies. Open Infect Dis J. 2012;6(1):46-51.

24. Gedik H, Şimşek F, Yıldırmak T, et al. Which multidrug resitant bacteria are emerging in patients with hematological malignancies?: OneYear Report. Indian J Hematol Blood Transfus. 2015;31(1):51-56.

25. Villafuerte-Gutierrez P, Villalon L, Losa JE, Henriquez-Camacho C. Treatment of febrile neutropenia and prophylaxis in hematologic malignancies: A critical review and update. Adv Hematol. 2014. http:// dx.doi.org/10.1155/2014/986938

26. Freifeld AG, Bow EJ, Sepkowitz KA, et al. Clinical practice guideline for the use of antimicrobial agents in neutropenic patients with cancer: 2010 Update by the Infectious Diseases Society of America. Clin Infect Dis. 2011;52:427-431.

27. Bucaneve G, Micozzi A, Menichetti F, et al. Levofloxacin to prevent bacterial infection in patients with cancer and neutropenia. N Engl J Med. 2005;353:977-987.

28. Kern WV, Klose K, Jellen-Ritter AS, et al. Fluoroquinolone resistance of Escherichia coli at a cancer center: Epidemiologic evolution effects of discontinuing prophylactic fluoroquinolone use in neutropenic patients with leukemia. Eur J Clin Microbiol Infect Dis. 2005;24:111-118.

29. Aslan S, Citak EC, Yis R, Degirmenci S, Arman D. Bacterial spectrum and antimicrobial susceptibility pattern of bloodstream infections in children with febrile neutropenia: Experience of single center in southeast of Turkey. Indian J Microbiol. 2012;52(2):203-208.

30. Trecarichi EM, Tumbarello M. Antimicrobial-resistant Gram-negative bacteria in febrile neutropenic patients with cancer: Current epidemiology and clinical impact. Curr Opin Infect Dis. 2014;27(2):200-210. 